\title{
Construct the Cloud Services Platform of Educational Resources to Achieve Regional Sharing of Educational Resources
}

\author{
Zhijun Liu ${ }^{1, a}$, Pengxi Li ${ }^{1, b}$, Ling Lu ${ }^{1, c}$, Lie Han ${ }^{1, d}$, Guili Zhang ${ }^{2, e}$ \\ ${ }^{1}$ Information Center, University of Electronic Science and Technology of China, Chengdu, 610054, \\ China \\ ${ }^{2}$ Modern Educational Technology Center, Southwest Petroleum University, Chengdu, 610500, \\ China \\ a liuzj@uestc.edu.cn, ${ }^{b}$ Ipx@uestc.edu.cn, ${ }^{c}$ linglu@uestc.edu.cn, ${ }^{d}$ hanlie@uestc.edu.cn, \\ ${ }^{\mathrm{e}}$ zhgl@swpu.edu.cn
}

Keywords: education cloud, educational resources, regional sharing.

\begin{abstract}
In recent years, with the rapid development and popularity of the Internet, some emerging network technologies bring a profound impact to information construction in higher education. The traditional teacher-centred instructional mode has been unable to meet the needs of modern education. Through construction of excellent course and open course, many colleges and universities have accumulated a large number of high-quality online educational resources, to build the cloud platform of educational resources that can support regional sharing. If using of appropriate sharing mode, it can improve the utilization of educational resources and accelerate the pace of universities education information.
\end{abstract}

\section{Introduction}

With the rapid development of Internet technology and multimedia technology, the traditional teaching and learning methods are being quietly changed. Education is undergoing a shift from traditional education to have a strong technical support modern education. Education is undergoing a shift from traditional education to modern education supported by a strong technical. The popularity of the Internet makes it possible that teaching and learning across time and space. New teaching mode driven by network technology was adopted by all types of schools because of its unique richness, interaction and fast transmission. On the basis of the traditional education model, it provides a variety of supplementary teaching means that provides a flexible, open, personalized diversified learning for students [1].

Currently, many universities have established the university's online education resource management platform by way of self-developed or purchased, and they carry out teaching activities assisted through the platform. Through construction of excellent course and open course, many universities in their own strengths disciplines have accumulated a large number of the high-quality teaching resources. However, due to the lack of a platform which unified and supported sharing in colleges and universities, many high-quality education resources did not play its due role.

In recent years, cloud computing appears which core philosophy is to provide hardware and software services on demand. Universities can run and use educational resources management system in the cloud platform without building their own dedicated data centre. It brings a new way of thinking and methods to achieve regional sharing of educational resources in universities [2].

\section{Overview of cloud computing}

Origins of cloud computing. In recent years, cloud computing is one of the hottest terms in the field of IT. The term first appeared in Google senior software engineer Christopher $•$ Bisciglia`s "Google $101 "$ project. In this project, he opened a course at his alma mater - the University of Washington that guides students to develop "cloud" system programming. With the deepening and development of the 
project, Google and IBM launched an ambitious collaboration in 2007 that included the distribution of many universities around the world in a massive network cluster. [3] Google calls such clusters "cloud", which is composed of hundreds of thousands or even millions of low-cost servers. Although the limited performance of a single server, such "cloud" has amazing processing power and data storage capacity due to the very large number [4].

Services framework of cloud computing platform. Cloud computing can provide the following three levels of service:

Infrastructure as a service (IaaS). IaaS refers to the available computer hardware resources are assigned to multiple users for payment. The resources such as servers, network, storage and data center space etc. are rent to the user according to the user's needs, and in accordance with the rent amount and using time to charge.

Platform as a service (PaaS). PaaS refers to provide a complete set of support software to users to form an available development platform. Users lease resources according to their needs in order to meet their demand for a special development platform.

Software as a service(SaaS). SaaS refers to directly provide the application software`s using function to a user. The user is using the specific software functions, without concerning about what kind of hardware is and what kind of system is used.

The main characteristics of the cloud computing system. Cloud computing systems are provided users as a service. Compared with traditional computer systems, cloud computing has the following main features:

Virtualization. With virtualization technology, cloud computing can integrate computing resources, storage resources, software and other resources together which distributed in various places, in order to achieve resources sharing.

Low cost. Cloud computing systems could package computer hardware and software resources into service. It is through pay-as ways to meet the needs of different users. Users could no longer buy expensive computer systems and software copyright which is low frequency of use. They reduce costs through hardware and software resources shared by multiple users.

On-demand service. Cloud computing systems provide users with various types of services. Users can choose services according to their specific circumstances. Cloud service providers can charge depending on the type and number of the service that selected by the user.

High availability. Cloud computing systems provide satisfactory services to users by integrating mass storage capacity and high performance computing. Cloud computing system can automatically detect failed nodes and automatically exclude them. Without affecting the normal operation of the system, it achieves high system availability.

\section{Module design of higher education resources cloud platform}

Ministry of education in the "Decade Development Plan of Education Information (2011-2020)" that read: We must strengthen the construction and application of Digital Campus. Through the use of advanced networks and information technology, we will integrate the resources to build advanced, efficient and practical education information infrastructure. We are going to develop and integrate of various high-quality educational resources. Resource construction and sharing system of higher education will be established. Information construction which include excellent course, sharing books and documents, teaching experiment platform will be advanced. We will have to improve college teacher`s application capabilities of educational technology, and promote universal application of information technology in teaching [5].

We propose to build the cloud platform of educational resources that can support regional sharing in order to provide a unified software and hardware platform for regional university. Universities share computing resources, while using cloud computing technology for data processing and storage. Teacher`s teaching resources will be stored in the cloud with be set up a shared type and shared scope 
[6]. This will facilitate the utilization of shared quality teaching resources, and improve utilization of the quality teaching resources.

Platform module design goals. The platform`s design aim to establish a cloud platform that would achieve regional sharing of education resources, improve the majority of university teachers' ability of applications and building on-line teaching resources, improve overall level of teacher's information teaching ability, promote the renewal of teaching concepts, achieve fast and convenient communication among teachers, between teachers and students, among students.

After registering through the network in the system, teachers can apply for courses. After review and approval by an administrator, teachers can use the course. Teachers can publish teaching resources about course in the cloud platform, can arrange online learning tasks and assignments, can check how students complete of the online learning tasks and jobs, can communicate with students through forums and message boards, and can manage students who learn the courses. Teachers can set sharing type of teaching resources that established by themselves. Meanwhile they can visit sharing resources that established by our school`s teachers and other school's teachers.

After registered in the system, students could apply for a course of learning. If get approval of teacher, they could access learning resources of the courses, complete learning tasks, submit assignments of teacher, discuss problems encountered in the course of learning forum. They also could visit sharing resources that established by our school's teachers and other school's teachers.

Administrators of school could approval of teacher's and student's application for registration, approval of teacher's application for registration of the course. They could inquiry teachers and students access records, select and recommend which sharing courses could be open to other colleges and universities.

The system administrator could create school users who allowed using the system, specify school's administrator, review and identify recommended sharing courses.

\section{Platform Module function}

\section{Service for teachers}

Teacher registration service. When teachers are ready to use the platform, they can fill out the registration information through the network online. The information will be reviewed by the university administrator. The user could log in after review by administrator.

Commencement application service. After teacher`s applications for registration were approved by university administrators, they could access the system by using account and password, log on to teacher`s interface. On this interface they can use the "Application Commencement" module to open courses. After teachers submit an application of opening course through the network, university administrators would check up for it.

The basic elements of curriculum management services. Teachers could manage the course name, course introduction, chapter structure, faculty, curriculum, teaching calendar, learning tasks, learning guides and so on.

Curriculum resource management services. After the opening of the course, course managers and other teachers in the same group can establish and maintain curriculum resources. Curriculum resources include: electronic textbooks, teaching plans, teaching videos, online exercises, and review questions and so on.

Uploaded curriculum resources are stored in the appropriate directory which classified by document form, while the relevant information is stored in the database.

Upload video and other teaching resources mainly are used MP4 video streaming format, and published by streaming media server. Platform can automatically identify the type of client user adoption, using the appropriate video player for playback. The platform can simultaneously store three kinds of bit rate for each video files. According to their network conditions, the audience can choose to watch high, medium, and low-resolution video.

Teachers can set sharing type of teaching resources they created. It can be: no sharing, shared campus, intercollegiate sharing. 
The chapter structure becomes the basic framework of lesson. Teachers will organize electronic textbooks, teaching plans, teaching videos, online exercises and any other teaching resources according to this framework in order to facilitate student learning.

Student management services. Teacher vet student's application to access the course. Once students approved, they can access curriculum resources, participate in discussion of the curriculum forums and so on.

Learning tasks and homework management services. Teachers can arrange learning tasks and homework online, and modify the learning task and homework layout, set whether to allow students to upload homework. Teachers can view how students complete learning tasks, and review homework submitted by student online. After teaching activities, teachers can delete homework submitted by students.

Message management services. After student access the course, they can leave a message to teachers if necessary. After the teachers login, they can read the leaved message in the "message management" and reply it.

Discussion questions management services. If students have any questions during the learning process, they can post them in the course forum. Students and teachers who have access to the curriculum can participate in discussions. After the teacher login, they can manage the curriculum forum.

\section{Services for students}

Student registration services. When students want to access resources of this system online, they can fill in the registration information through the network.

Student's registration may also be in a way of bulk. Students fill in personal information in an Excel spreadsheet in accordance with the prescribed format. Then university administrators import form into the system directly.

Application to access courses services. After students successfully registered in the system and approved, they may apply for access to courses of interest. A student can apply for access to one course. He can also apply for access to many courses.

After students apply for curriculum, teachers can verify of the student`s application. Then students can access into the curriculum.

Curriculum resources browsing service. After application of accesses course is approved by teachers, students can log curriculum, access to learning resources. Students browse curriculum resource in accordance with learning tasks teacher arranged. The system can automatically record the dynamic process of student learning.

Homework submission service. While course suitable adopt electronic documents to submit course work, students may be asked to submit homework online. After the homework is submitted, students can modify their homework before the teacher correct.

Message service. During the learning process, students can leave message to teacher if necessary.

Discussion service. If students have questions in the learning process, they can post in the course forum for discussion.

\section{Service of university administrators}

Each school is set a university administrator who can managed registered students and teachers in the school. And he also can manage curriculum resources created by teachers.

Teacher management services. University administrator can verify teacher`s application for registration in this module and manage the registered teachers.

Firstly, the university administrator fills teacher's personal information in an Excel spreadsheet in accordance with the prescribed format. Then he imports form into the system directly.

Student management services. University administrator can verify student's application for registration in this module and manage the registered students.

Firstly, the university administrator fills student's personal information in an Excel spreadsheet in accordance with the prescribed format. Then he imports form into the system directly. 
Curriculum management services. University administrator can verify teacher`s application for open courses in this module. Teachers can manage their courses in the system after verified. University administrator also can inquire, edit, and delete courses which have been approved in this module.

Curriculum resource management services. Generally speaking, curriculum resources should be managed by the teachers in curriculum group. If necessary, the administrator can also directly manage the courses resources that created by a school teacher in the system.

Comments management services. In this module, university administrator can monitor student's comments in the courses. If sensitive information appeared, it can instantly be shielded.

Discussion management services. In this module, university administrator can manage the school curriculum forum that set by school teachers.

\section{Service of system administrator}

System announcement service. This module is used by system administrator to release important information and announcements to the system-wide. The announcement which has been issued can be edit, deleted and other operations.

School management services. This module can be used to manage the school which added to the system. The main functions are: add schools, set access account and password for university administrator, reset university administrator`s password.

Data backup services. This service is for backup important data in the systems, including database data and upload files. To prevent data loss unexpectedly, the system administrator not only can backups the database data regularly in this module, but also backup teacher`s uploaded files by a way of compression downloads.

\section{Summary}

Building the cloud platform of educational resources that can support regional sharing can achieve sharing of digital excellent teaching resources; it also can improve the utilization of teaching resources [7]. University teachers who join the sharing platform can apply to open course. After the opening of the course, course supervisors and other teachers in the groups can establish and maintain the curriculum resources on the platform. They conduct educational activities through the platform. Teachers and students of the university can communicate through the platform, and give full play to the advantages of the university disciplines. This will promote regional sharing of quality education resources between each other colleges and universities, and drive to improve the quality of higher education as a whole.

\section{Acknowledgements}

The research work was supported by Teaching Reform Project of University of Electronic Science and Technology of China: Project NO.2010XJYZC036 and Project NO. 2010XJYYB024 and Teaching Reform Project of Sichuan Provincial: Research and Practice of the Multi Network Teaching Space Construction Based on Information Technology.

\section{References}

[1] Ministry of Education. National long-term Education Reform and Development Plan (2010-2020).

[2] Bai Yunjuan, Shen Shushing. Cloud Learning: Learning Concept Stimulated by Cloud Computing. China Educational Technology, 08, pp. 14-18, 2011.

[3] Ke Dongliang, Zheng Xiao, Li Qiao. Cloud Computing: Instances Research and Key Technology. Journal of Chinese Computer Systems, 11, pp. 2321-2329, 2012. 
[4] Tang Yueming, Zha Hongbo. Research on the Construction of independent learning systems in mobile cloud environments. Distance Education in China, 01, pp.83-88, 2014.

[5] Ministry of Education. The Ministry of Education on The Issuance of "Decade Development Plan of Education Information (2011-2020)".

[6] Zhang Huainan, Yang Cheng. Research Review of Cloud Computing in Education in China. Distance Education in China, 01, pp. 20-26, 2013.

[7] Zhang Jingtao, Ding Xin. Investigation Report on Digital Campus and Support Service System in Primary and Middle Schools in America and Hong Kong. China Educational Technology, 02, pp. 22-24, 2012. 